\title{
Dysplasia-associated polypoid mucosal lesion in a pelvic pouch after restorative proctocolectomy for ulcerative colitis
}

Hugh Freeman MD

\begin{abstract}
H Freeman. Dysplasia-associated polypoid mucosal lesion in a pelvic pouch after restorative proctocolectomy for ulcerative colitis. Can J Gastroenterol 2001;15(7):485-488. A 32-yearold man with ulcerative colitis had a colectomy for toxic colitis. Later, a rectal mucosectomy was performed along with the creation of a pelvic pouch. In 1998, approximately 10 years after this staged restorative proctocolectomy was completed, endoscopic examination of the pelvic pouch detected a small mucosal polypoid mass lesion. Although the lesion had the macroscopic appearance of an inflammatory polyp, microscopic sections of the resected lesion revealed dysplastic changes. Endoscopic polypectomy was performed to remove the lesion, and further histological surveillance examinations of the pelvic pouch have not detected additional dysplastic mucosal changes.
\end{abstract}

Key Words: Colon cancer; Colon polyps; Dysplasia; Dysplasiaassociated mass lesion; Endoscopic surveillance; Intestinal cancer; Pelvic pouch; Restorative proctocolectomy; Ulcerative colitis

\section{Lésions muqueuses polypoïdes dysplasiques affectant une poche pelvienne après proctocolectomie de reconstruction pour colite ulcéreuse}

RÉSUMÉ : Un homme de 32 ans, souffrant de colite ulcéreuse, a subi une colectomie pour colite toxique. Plus tard, une mucosectomie rectale avec construction de poche pelvienne a été effectuée. En 1998, soit environ 10 ans après cette proctocolectomie de reconstruction par étapes, l'examen endoscopique de la poche pelvienne a permis de déceler une petite lésion sous forme de masse muqueuse polypoïde. Bien que la lésion ait eu l'aspect macroscopique d'un polype inflammatoire, les sections microscopiques de la lésion réséquée ont révélé la présence d'anomalies dysplasiques. Une polypectomie endoscopique a été effectuée pour exciser la lésion et la poursuite des examens histologiques de la poche pelvienne n'a pas permis de déceler d'autres anomalies muqueuses de type dysplasique.
Prior studies have firmly established that ulcerative colitis 1 predisposes a person to the development of colon cancer, especially in patients with long-standing pancolitis (13). Others have suggested that the onset of malignancy may be preceded by atypical epithelial changes or dysplasia, and it has been postulated that detection of these may enable treatment to be instigated before the development of frank carcinoma (4). It was initially believed that proctocolectomy and rectal mucosectomy would eliminate the risk of later colon cancer. However, rare cases of carcinoma developing in the ileostomy stoma mucosa after total procto- colectomy and conventional ileostomy have been reported (5-7); in these cases, it was postulated that colonic metaplasia of the ileal epithelium occurred (8), possibly related to ileal stasis. Later, it was recognized that even with restorative proctocolectomy after rectal mucosectomy and creation of a sewn anastomosis, up to $20 \%$ of patients may have residual islets of colonic epithelial cells $(9,10)$. In recent years, a stapled, rather than sewn, anastomosis has also been performed. As a result, rectal cuff mucosa has been left in situ, with, presumably, a persistent risk of neoplastic transformation. Indeed, in 1990, a case of cancer in an ileoanal 


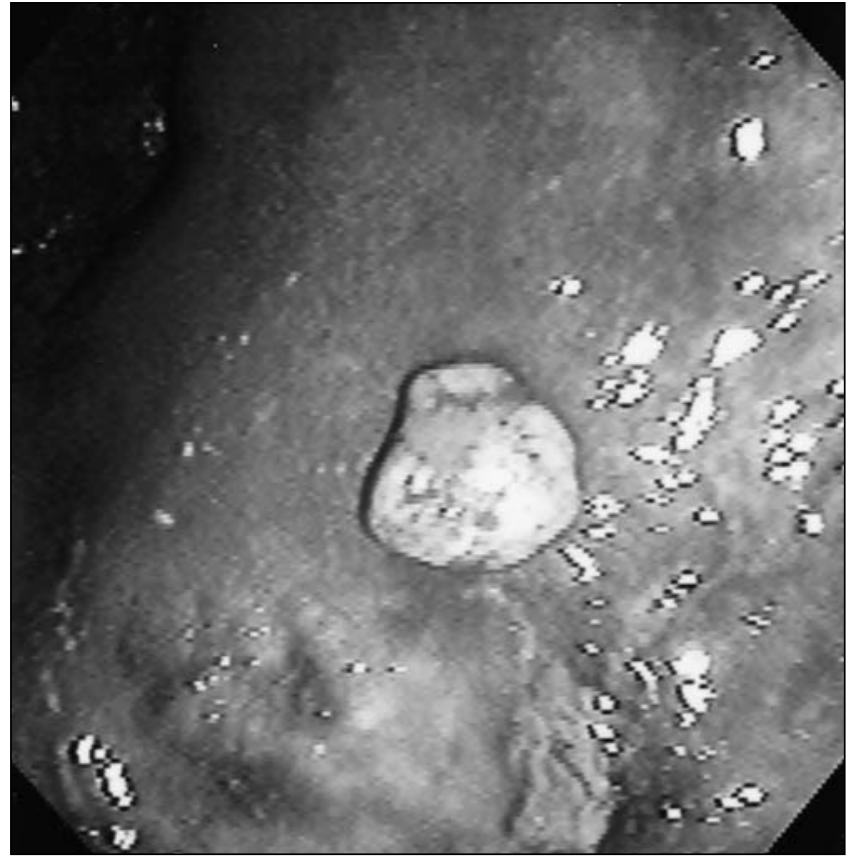

Figure 1) Polypoid lesion in the pelvic pouch mucosa. The polyp is slightly irregular, friable and focally ulcerated

reservoir was described, which is thought to have originated from the rectal cuff, even though a distal rectal mucosal proctectomy had been performed (11). Other similar cases, believed to have arisen from rectal mucosa, have also been described $(12,13)$. Interestingly, a large cell lymphoma in the pelvic pouch after restorative proctocolectomy has been described (14), as well as an invasive adenocarcinoma in a long-standing Kock continent ileostomy (15). Most recently, neoplastic changes in pelvic pouch epithelium have been detected in endoscopic biopsies of the pelvic pouch, along with DNA aneuploidy using flow cytometric methods (16).

The present report describes a patient with ulcerative colitis and a neoplastic polyp originating from the pelvic pouch epithelium rather than the region of the pouch-to-anal anastomosis. This was detected over the course of a decade, after a total colectomy for toxic colitis was performed, followed by rectal mucosectomy and pelvic pouch reconstruction using a hand-sewn, rather than stapled, anastomosis.

\section{CASE PRESENTATION}

A 32-year-old man had a colectomy in August 1987 for toxic colitis. Pathological evaluation of the resected colon showed changes of ulcerative colitis with pseudopolypoid changes. No dysplastic or other neoplastic lesions were detected in the resected colon. There was no family history of colorectal neoplasia. In March 1988, a rectal mucosectomy was performed, along with the creation of a pelvic S-pouch and loop ileostomy. A sewn (rather than stapled) pouch-to-anal anastomosis was performed. In September 1988, the ileostomy was closed. After this staged procedure,

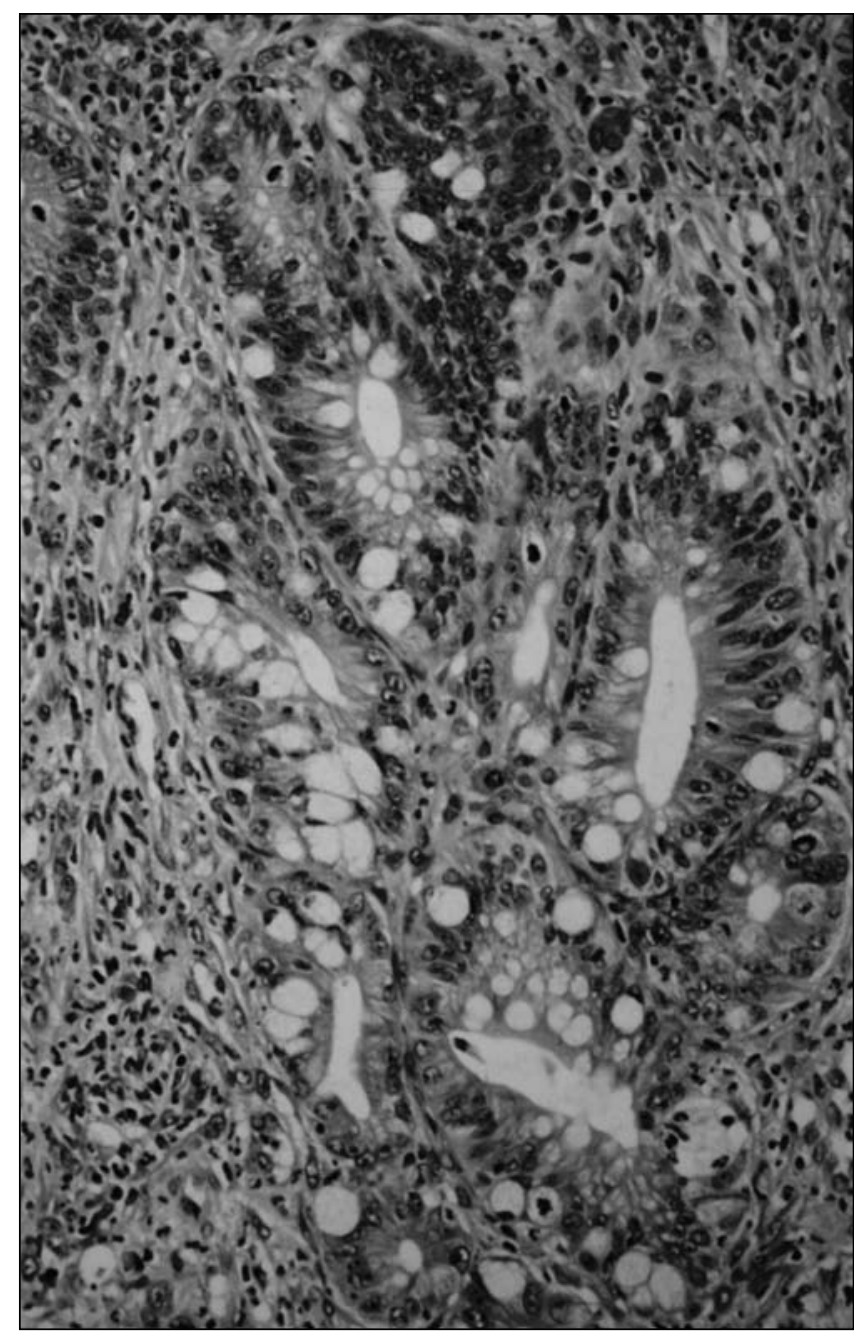

Figure 2) Dysplastic colonic epithelium in the resected polyp

the patient did well, although he continued to have four to six bowel motions daily with no nocturnal diarrhea or soilage. In June 1991, the anastomosis between the anus and the pouch became strictured and was dilated. Endoscopic examination of the pelvic pouch revealed erythematous and friable mucosa with a few scattered erosions, consistent with pouchitis. Treatment with oral metronidazole for one month led to complete resolution of the endoscopic changes. In June 1992, he was reviewed and was doing well; he was having four daily bowel movements, and endoscopic evaluation of the pelvic pouch was normal. Random biopsies of the pelvic pouch mucosa were also normal. In 1998, about 10 years after his colectomy and pelvic pouch reconstruction, endoscopic examination of the pelvic pouch revealed mucosal erythema but no erosions. However, a distinct, slightly irregular, $1 \mathrm{~cm}$ polypoid lesion was seen in the pelvic pouch, approximately $5 \mathrm{~cm}$ from the anal anastomosis (Figure 1). The surface of the polyp was covered with apparent exudate, suggesting an inflammatory lesion. Histological examination of the completely excised polyp (by snare electrocautery), however, was reported to show dysplastic change (Figure 2). In 1999, he was reviewed again on two occasions. He was doing well, and 
endoscopic evaluations of the pelvic pouch revealed only some mucosal hyperemia, and multiple mucosal biopsies from different sites in the pelvic pouch mucosa showed no further dysplastic changes (Figure 3).

\section{DISCUSSION}

In theory, proctocolectomy and rectal mucosectomy for ulcerative colitis eliminates the risk of developing carcinoma. However, it has been demonstrated that residual rectal mucosa may still be present, even after apparently complete mucosal stripping and creation of a hand-sewn, rather than stapled, anastomosis. In 1990, rectal carcinoma in an ileoanal reservoir was reported (11). The authors believed that this carcinoma developed from the rectal mucosal cuff rather than from the mucosa of the pelvic pouch per se. Similar conclusions have been recorded in other cases $(12,13)$. In addition, even after conventional proctocolectomy and ileostomy, carcinoma in the ileal mucosa has been observed (5-7). And, more recently, invasive adenocarcinoma in a continent ileostomy associated with a Kock pouch was described (15). These findings have provided indirect evidence that the ileal pouch mucosa per se may also be subsequently at risk for neoplastic change.

In 1991, Lofberg et al (16) from Sweden described dysplastic mucosal changes and DNA aneuploidy in a pelvic pouch. It was later suggested that pelvic pouch mucosa with severe villous atrophy accompanied by longstanding pouchitis ('type C' mucosal adaptation) is at special risk for neoplastic change (17). In addition, in a report of pelvic pouch patients who underwent surveillance endoscopic studies, this same Swedish group described five patients with dysplastic changes in flat, atrophic pelvic pouch mucosa; in one of these patients, high grade dysplasia was observed at multiple mucosal sites within the pelvic pouch (18). Although contrasting results describing failure to detect dysplastic change in ileal mucosa have been reported in some surveillance programs for pouch mucosa, even with detailed histological evaluation and DNA cytometric analysis $(19,20)$, the first carcinoma has recently been described in pelvic pouch mucosa, requiring pouch removal (21). In the present report, a macroscopically visible polypoid lesion was detected, which contained dysplastic epithelium. If this had been detected in the colon during the course of ulcerative colitis, it would have fulfilled criteria for a 'dysplasia-associated mass lesion', and colectomy would have been recommended. In the present patient, this polypoid lesion was removed endoscopically and subsequent pelvic pouch examinations have not revealed recurrent dysplastic changes or invasive carcinoma.

The present report raises a number of important clinical issues relevant to the long term follow-up of patients with a pelvic pouch and the potential need for ongoing histomorphological surveillance. First, is endoscopic surveillance necessary or appropriate in all of these patients or are there subgroups who are at higher risk who could benefit from repeated evaluation, especially if their postoperative clinical course is satisfactory? In 21 patients followed in the

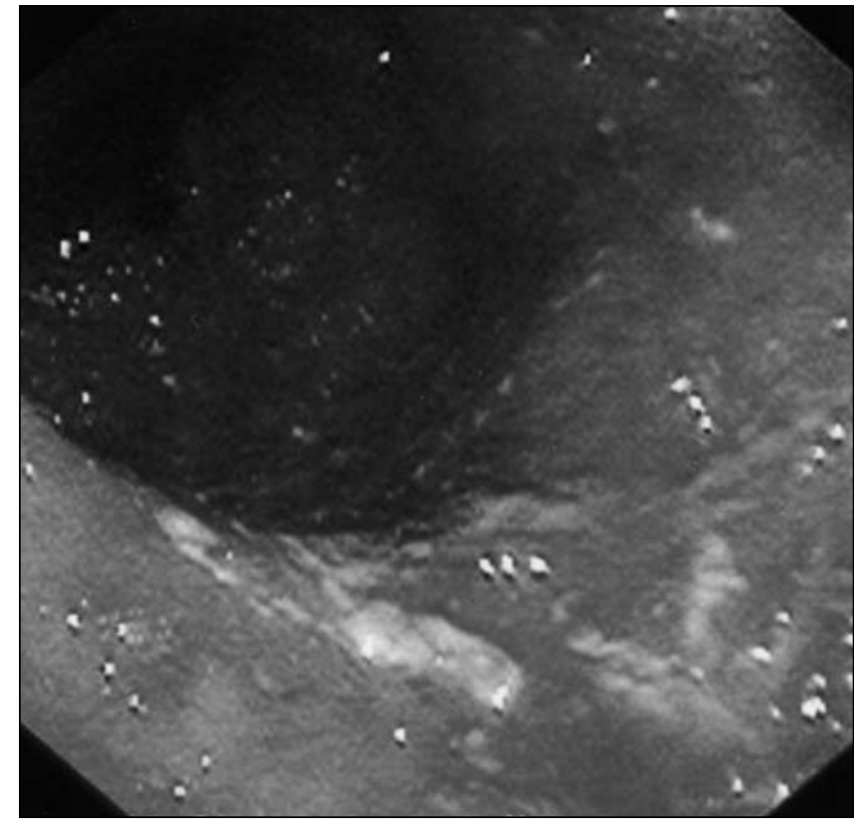

Figure 3) Endoscopic view of the polypectomy site. Only erythema of the pelvic pouch is now present

Swedish study mentioned previously, prior history of colon cancer or dysplasia in the resected colon was not predictive of subsequent pelvic pouch dysplasia (18). However, the development of persistent, severe, 'type C' mucosal atrophy in the pelvic pouch mucosa was thought to be significant and could be used to reselect a group of patients who are at high risk for neoplastic transformation of the pouch mucosa (18). Other selection factors - for example, concomitant hepatobiliary tract disease, ie, sclerosing cholangitis, which is thought to increase the risk of colorectal cancer in ulcerative colitis - also need to be explored. Second, if dysplastic changes are detected, then what should be done? In the present patient, a polyp, which had the appearances of an inflammatory polyp, was endoscopically resected; histological evaluation, however, revealed focal dysplastic change. Follow-up over the next two years did not demonstrate any persistent or recurrent dysplastic changes. In a patient who had a satisfactory result after completing a multistage procedure, removing the pelvic pouch would be difficult. Third, if histomorphological surveillance is to be performed, information is even needed on some technical issues, eg, the numbers of biopsies to be done and the sites of biopsy within the pouch. In spite of the positive experience from some, but not all, centres that perform multiple-site biopsy surveillance in patients with longstanding ulcerative colitis, a universally accepted approach is still not available or followed. For pelvic pouch patients, data from large centres will be needed before evidence-based recommendations can be provided. In the interim, however, current enthusiasm for pelvic pouch reconstructive surgery in patients with ulcerative colitis may have to be tempered with the knowledge that the risk of neoplasia and the possible need for future surveillance are not necessarily being eliminated. 


\section{REFERENCES}

1. Langholz E, Munkholm P, Davidsen M, Binder V. Colorectal cancer risk and mortality in patients with ulcerative colitis. Gastroenterology 1992;103:1444-51.

2. Gyde SN, Prior P, Allan RN, et al. Colorectal cancer in ulcerative colitis: a cohort study of primary referrals from three centres. Gut 1988;29:206-17.

3. Henricksen C, Kreiner S, Binder V. Long term prognosis in ulcerative colitis - based on results from a regional patient group from the county of Copenhagen. Gut 1985;26:158-63.

4. Riddell RH, Goldman H, Ransohoff DF, et al. Dysplasia in inflammatory bowel disease: standardized classification with provisional clinical applications. Hum Pathol 1983;14:931-68.

5. Baciewicz F, Sparberg M, Lawrence JB, Poticha SM. Adenocarcinoma of an ileostomy site with skin invasion: a case report. Gastroenterology 1983;84:168-70.

6. Bedetti C, DeRisio VJ. Primary adenocarcinoma arising at an ileostomy site. An unusual complication after colectomy for ulcerative colitis. Dis Colon Rectum 1986;29:572-5.

7. Smart PJ, Sastry S, Wells S. Primary mucinous adenocarcinoma developing in an ileostomy stoma. Gut 1988;29:1607-12.

8. Berman JJ, Ullah A. Colonic metaplasia of ileostomies. Biological significance for ulcerative colitis patients following total colectomy. Am J Surg Pathol 1989;13:955-60.

9. Heppell J, Weiland LH, Perrault J, Pemberton JH, Telander RL, Beart RW Jr. Fate of the rectal mucosa after rectal mucosectomy and ileoanal anastomosis. Dis Colon Rectum 1983;26:768-71.

10. Allen DC, Biggart JD. Misplaced epithelium in ulcerative colitis and Crohn's disease of the colon and its relationship to malignant mucosal changes. Histopathology 1986;10:37-52.

11. Stern H, Walfisch S, Mullen B, McLeod R, Cohen Z. Cancer in an ileoanal reservoir: a new late complication? Gut 1990;31:473-5.

12. Puthu D, Rajan N, Rao R, Rao L, Venugopal P. Carcinoma of the rectal pouch following restorative proctocolectomy. Dis Colon Rectum 1992;35:257-60.

13. Sequens R. Cancer in the anal canal (transitional zone) after restorative proctocolectomy with stapled ileal pouch-anal anastomosis. Int J Colorectal Dis 1997;12:254-5.

14. Nyam DC, Pemberton JH, Sandborn WJ, Savcenko M. Lymphoma of the pouch after ileal pouch-anal anastomosis: report of a case. Dis Colon Rectum 1997;40:971-2.

15. Cox CL, Butts DR, Roberts MP, Wessels RA, Bailey HR. Development of invasive adenocarcinoma in a long-standing Kock continent ileostomy: report of a case. Dis Colon Rectum 1997;40:500-3.

16. Lofberg R, Liljeqvist L, Lindquist K, Veress B, Reinholt FP, Tribukait B. Dysplasia and DNA aneuploidy in a pelvic pouch. Dis Colon Rectum 1991;34:280-4.

17. Veress B, Reinholt FP, Lindquist K, Lofberg R, Liljeqvist L. Long-term histomorphological surveillance of the pelvic ileal pouch: dysplasia develops in a subgroup of patients. Gastroenterology 1995;109:1090-7.

18. Gullberg K, Stahlberg D, Liljeqvist L, et al. Neoplastic transformation of the pelvic pouch mucosa in patients with ulcerative colitis. Gastroenterology 1997;112:1487-92.

19. Pronio A, Montesani C, Vecchione A, et al. Restorative proctocolectomy: histological assessment and cytometric DNA analysis of ileal pouch biopsies. Hepatogastroenterology 1997;44:691-7.

20. Sarigol S, Wyllie R, Gramlich T, et al. Incidence of dysplasia in pelvic pouches in pediatric patients after ileal pouch-anal anastomosis for ulcerative colitis. J Pediatr Gastroenterol Nutr 1999;28:429-34.

21. Vieth M, Grunewald M, Niemeyer C, Stolte M. Adenocarcinoma in an ileal pouch after prior proctocolectomy for carcinoma in a patient with ulcerative pancolitis. Vichows Arch 1998;433:281-4. 


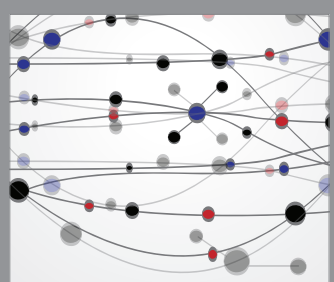

The Scientific World Journal
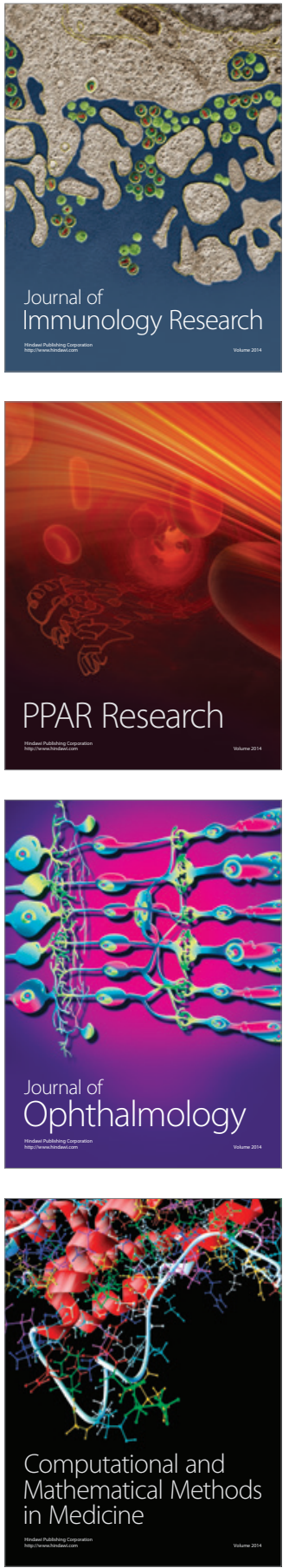

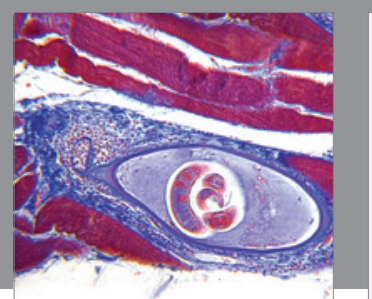

Gastroenterology Research and Practice

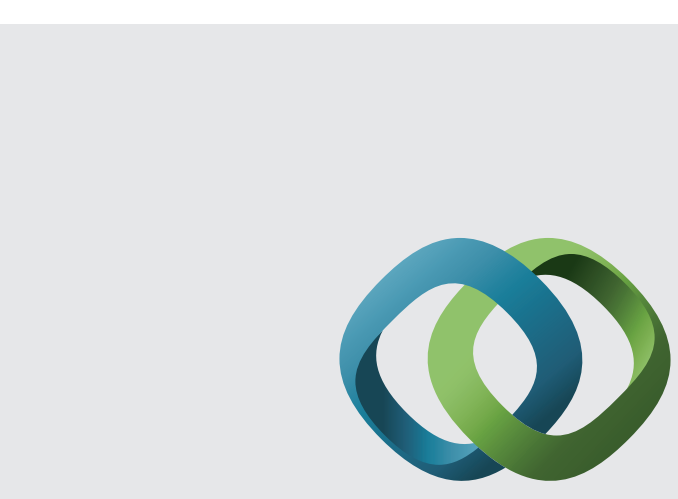

\section{Hindawi}

Submit your manuscripts at

http://www.hindawi.com
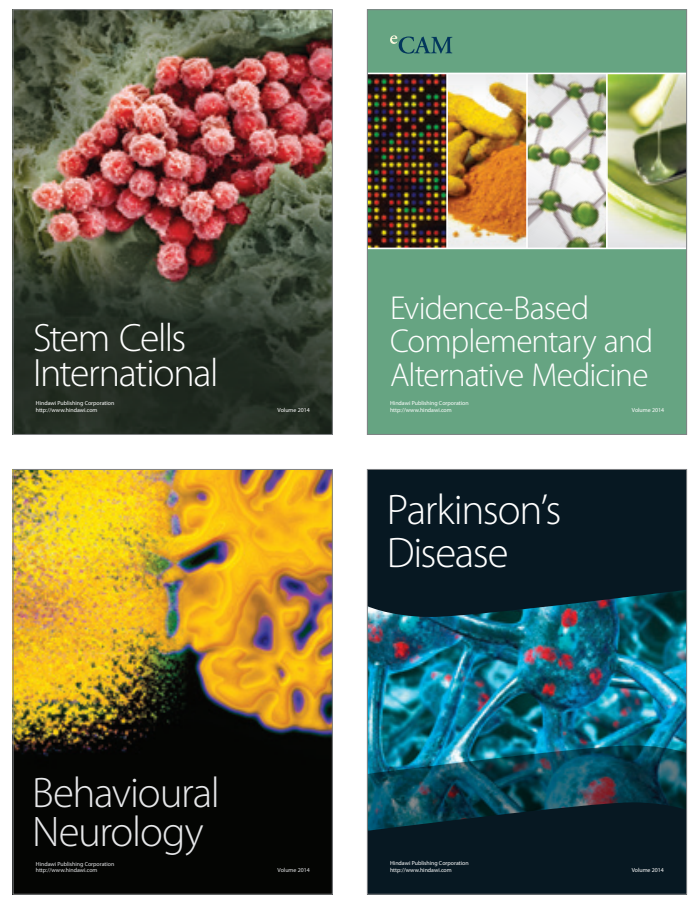
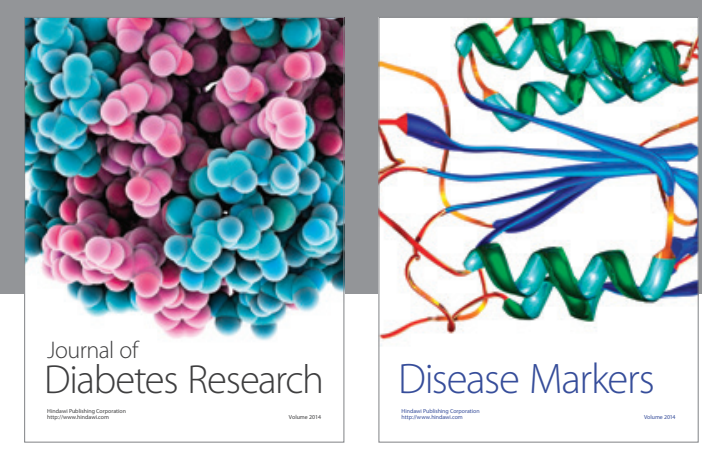

Disease Markers
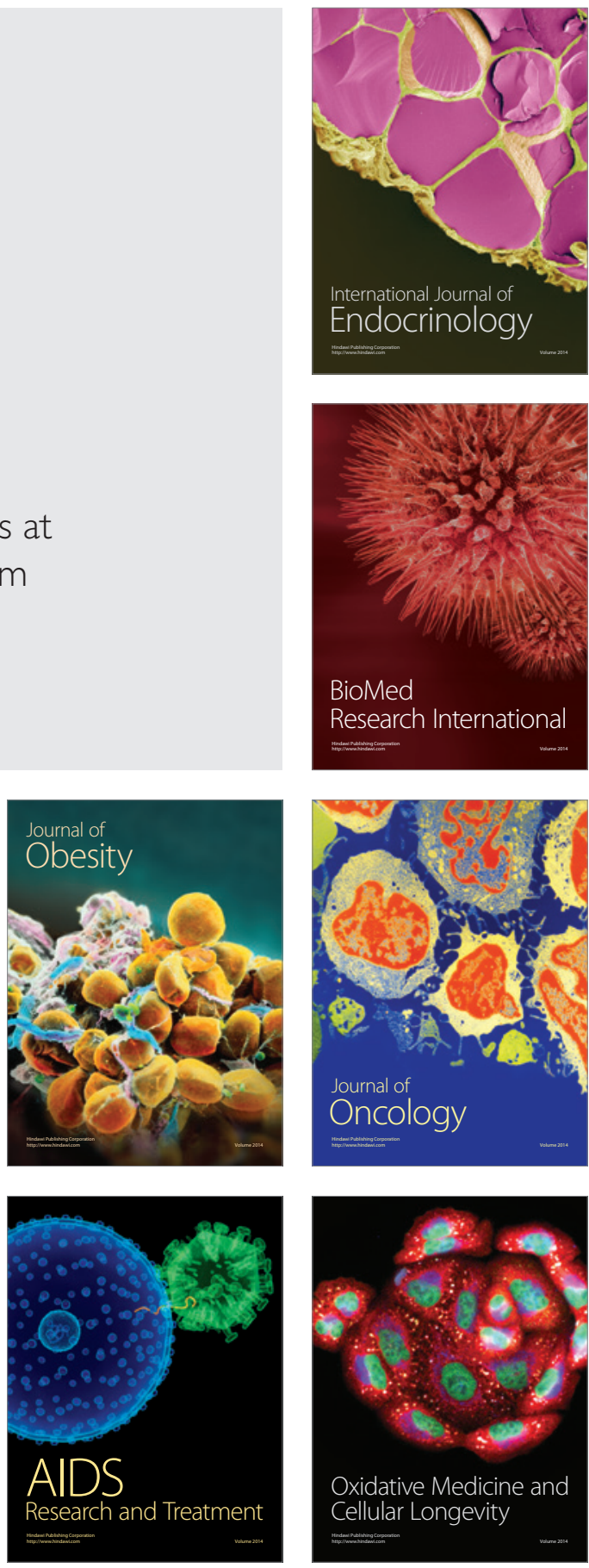